\title{
Which Factors Can Stimulate China's Green Transformation Process? From Provincial Aspect
}

\author{
Herui Cui, Xueying Liu*, Qiaozhi Zhao \\ School of Economics and Management, North China Electric Power University, \#619 Yonghua Street, Baoding China
}

Received: 2 January 2020

Accepted: 18 April 2020

\begin{abstract}
Stimulation of green transformation is of great significance for central government in order to realize high-quality development in China. Green total factor productivity (GTFP) is evaluated among provinces during 2000 2017 to indicate their trends and find out their key driving factors. Results are as follows: First, Chinese green transformation performance turns better as GTFP grows slightly in the research period in a whole. Technical progress is the most contributor source and technical efficiency is in the second order. Second, provincial green transformation performances obey typical 'one-peak' distribution curve. Its peak point moves to the right and downward directions from the horizontal and vertical axis. Third, as parameter results of the dynamic panel data econometric model, economic agglomeration leads to positive effects on GTFPs significantly. Enlarging economic agglomeration is an important development potential to accelerate green transformation performance. Meanwhile, regional heterogeneity among eastern, central and western in China should be considered in details to comprehensively this transformation process. For eastern region, making the full use of its significant advantages in R\&D environment, endowment and achievement accumulation should be the best choice while for the central and western regions, absorbing from eastern or foreign technology may be more economic. The coordinated development of different regions will release more development opportunities for China in the future.
\end{abstract}

Keywords: green total factor productivity, economic agglomeration, kernel density estimation, green technology innovation

\section{Introduction}

As China enters into high-quality development stage nowadays, stimulating its wholly green transformation performance has attracted more and more attention globally. It is also an important subject for realizing its energy-saving and emissions reduction targets [1].

*e-mail: 779715497@qq.com
While China's economy has experienced a long period of rapid growth, problems such as energy shortage and environmental deterioration have become increasingly prominent. These restrict the sustainable development of the economy [2]. Due to the large amount of energy consumption, China's $\mathrm{CO}_{2}$ emission has ranked first in the world in 2007. Air pollution caused by industrial emissions and traffic jams has brought diseases to people [3]. Accelerating the transformation of industrial structure from extensive development model to intensive 
development model is an inevitable requirement of green development [4]. China urgently needs to take the green transformation road dominated by the promotion of GTFP. It has become an important academic topic to explore the evaluation criteria and influencing factors of China's green development.

For a long time, the efficiency of China's economic operation has obvious differences due to huge regional differences in resource endowment, development stage and technological innovation. China's $13^{\text {th }}$ Five-Year Plan for environmental protection also sets emissions requirements for each province. At the same time, the economic relations between regions are getting closer and closer, and regional economic agglomeration continues to strengthen [5-7]. Economic agglomeration is the product that regional economic develops to certain stage. It refers to the phenomenon that economic activities are relatively concentrated in a certain geographical area $[8,9]$. On the whole, the agglomeration degree of each Chinese province has increased to a certain extent. Economic agglomeration is highly correlated with economic growth level, but whether economic agglomeration has a positive or negative impact on green economic development is controversial [10-13]. Therefore, an empirical study on economic agglomeration and GTFP can better understand the relationship between economic agglomeration and green transformation performance.

From the above, this research first calculates the GTFP index and its decomposition items in China's provincial areas, and analyzes its dynamic evolution characteristics. Secondly, on the basis of GTFP measurement, economic agglomeration is included in the influencing factors, and dynamic panel model is used to empirically test the influencing results. Finally, according to the empirical results and analysis put forward to promote China's regional economic green coordinated development policy recommendations.

\section{Literature Review}

In the existing literature, the evaluation of green transformation performance can be reflected from many perspectives. For example, Kuman et al. combined BWM (Best Worst Method) and VIKOR (VlseKriterijuska Optimizacija I Komoromisno Resenje) methodologies to discuss the green performance evaluation of airports, and concluded that green policies and regulations were the most important performance standards of green airports [14]. Hou et al. conducted an empirical study on the dynamic threshold effect of industrial green transformation on carbon intensity under different degrees of environmental regulation. The results showed that the carbon intensity of Chinese industry decreased during the study period and gradually realized green transformation [15]. Yin et al. considered the transformation of building materials industry to green building materials industry. The multi-stage governance mechanism of green transformation was studied by establishing the dynamic game model of building materials enterprises, governments, building developers and building consumers and the numerical simulation experimental method [16]. Feng and Wang used GTFP to evaluate the green transformation performance of China's metal industry and put forward policy recommendations on the effective implementation of the green development transformation of China's metal industry [17]. Feng et al. took green industrial restructuring and GTFP as targets to achieve the growth of ecological welfare performance [18]. Shao et al. studied on industrial GTFP in Shanghai indicated that the green trend of industrial technology change in Shanghai was unstable and the green transformation of industrial development model needed to be further promoted [19].

Research on GTFP began in the middle and late $20^{\text {th }}$ century. The directional distance function introduced by Chung et al., based on the fundamental assumption of consumer preference, directly incorporated pollution emissions into the production technology as non-expected outputs [20]. Färe et al. established a mathematical model of environmental production function, and environmental directional distance function, and verified it with the data of American coalfired power plants [21]. However, most of these studies were based on European or American data, without accounting for China's GTFP. In recent years, some Chinese scholars also try to consider the environment and resources into the connotation of total factor productivity. For example, Chen calculated the TFP and green growth of China's industrial industry by using Solow residual method in consideration of carbon dioxide emissions, and concluded that China's industry as a whole had changed to an intensive growth mode [22]. There are two kinds of GTFP measurement in existing literatures single factor index and multi-factor index. The single factor index ignores the substitution of capital and labor for energy input, which has some deficiencies [23]. Therefore, the method of integrating capital, labor and other input factors into the production function to measure TFP of the environment has been widely applied. In the production process, not only will the "good" output be produced, but also the "bad" output, that is, the non-expected output, such as the emissions of industrial wastewater, industrial sulfur dioxide and industrial smoke and dust [24]. Among the existing studies on the construction of GTFP measurement models, stochastic frontier analysis method (SFA) and data envelop analysis method (DEA) are mainly included. Among them, SFA method is a typical parameterization method. Wang et al. used SFA-Malmquist method and spatial econometric analysis to calculate the GTFP level of each province in China, and believed that technical progress played a greater role than technological efficiency in the growth of GTFP in China [25]. Jin et 
al. calculated the GTFPs of 278 prefecture-level cities in China through SFA model, and found that there was an inverted u-shaped relationship between county-level government competition and prefecture-level GTFP [26]. And this relationship had a strong robustness. As one of the methods to evaluate input-output efficiency, DEA model has an absolute advantage in dealing with the effectiveness evaluation of multi-input and multi-output, so it has become the mainstream method of efficiency evaluation [27]. Liu et al. used DEA and global Malmquist-Luenberger productivity index methods to analyze the change trend of energy productivity growth in China's Pearl River delta region, and the results showed that there were differences in energy productivity growth in the Pearl River delta region, and the growth rate was improved during the study period [28]. Feng and Huang used DEA method and Global Malmquist index to measure and analyze GTFP in China's metal industry. From 2000 to 2015, GTFP in China's metals industry was found to have increased, with technical progress as a key driver [29]. DEA method also includes many models, such as directional distance function (DDF) and slack based measure (SBM) model. The DDF model encourages the expansion of expected output to the production front, assuming that pollution emissions are minimized, consistent with the concept of sustainable production processes. Fu and Geng combined GTFP with DDF model and divided green development into two parts: green development model and green development effect, and they studied the impact of public participation and regulation compliance on green development [30]. The SBM model is widely used because it can deal with the non-expected output in a non-angular and nonradial way, and can better solve the problem of nonexpected output in the evaluation process and the relaxation problem of input-output [31]. Cecchini et al. used the SBM method and life cycle analysis (LCA) results from 10 dairy farms in Umbria (Italy) to assess their environmental efficiency and emission reduction potential [32].

The research on the driving factors of GTFP started late, and relevant empirical research began to develop in recent years. Few authors specifically study the influencing factors of GTFP, and most of the sources are auxiliary research on the basis of measurement. Econometric methods are widely accepted as studying tools [33, 34]. Using the dynamic panel regression method, Wang and Sun studied the impact and mechanism of environmental policy tightening on GTFP growth in the industrial sector in OCED countries. The research results verified porter's hypothesis that, at a certain level, environmental policies have a positive impact on GTFP, and beyond a certain level, environmental regulatory policies will have an adverse impact [35]. Lin and Chen took factor market distortion as the core explanatory variable to study its adverse impact on China's green development. It was found that although factor market distortion promoted economic development, it resulted in environmental pollution and low productivity [36]. As can be seen from the above literature, the influencing factors and mechanisms of GTFP are relatively complex. Some scholars also studied the impact of economic agglomeration on the efficiency of green economy. Economic agglomeration is a form of economic development, and it will be formed when the economy develops to a certain stage [37]. Agglomeration promotes economic growth as the promotion effect of agglomeration. But it can also result in crowding and inefficiency due to environmental pollution, resource constraints and congested public infrastructure. Lin et al. used the panel data of 285 prefecture-level cities in China from 2004 to 2016 to measure the efficiency of green economy, and analyzed the impact of economic agglomeration on the efficiency of green economy at the urban level in China. The influence of economic agglomeration on the measurement index of economic growth, resource conservation and environmental protection was nonlinear [38].

This research attempts to expand the existing literature from the following aspects. (1) Energy input and environmental pollution are included in the calculation of GTFP. If the value is larger, the efficiency of green economy development is relatively higher. Therefore, GTFP is adopted in this research to evaluate green transformation performance. In terms of the model construction of GTFP, the non-expected output of this research adopts a variety of pollutants to replace the single pollutant adopted by most scholars. In other words, industrial $\mathrm{SO}_{2}$, industrial wastewater and industrial smoke and dust emissions are included in the measurement model to better reflect the green concept. And the method of SBM-ML index is used to decompose. (2) In terms of the selection of influencing factors, this research considers economic agglomeration as one of the influencing factors and focuses on analyzing the impact of economic agglomeration on GTFP. (3) In the construction of panel model, the change of any factor itself has certain inertia, and the results of the previous phase often affect the results of the later phase. In this research, the main influencing factors on the provincial GTFP are identified through the method of dynamic panel with system GMM (SYSGMM) model.

The rest of this research is arranged as follows: In Section 3, DEA-SBM and $M L$ index methods are used to estimate GTFP index as green transformation results. Kernel density is utilized to analyze detailed dynamic trends among 30 provinces during 2000 2017. In Section 4, SYS-GMM is applied to find out key influential factors of GTFPs. The main conclusions and policy recommendations are supplied in Section 5. 


\section{GTFP Evaluation Model and Dynamic Trends}

\section{DEA-SBM and $M L$ Index Methods}

As one non-parametric framework, DEA is widely used in latest performance evaluation research. SBM is one branch of DEA which handles with undesirable outputs [39]. In our research, three outputs are considered and they are industrial wastewater, industrial $\mathrm{SO}_{2}$ and industrial smoke and dust emissions.

The model constructs the production frontier by treating each region as a basic decision making unit (DMU). We assume that $p$ regions in $t$ periods produce $M$ expected outputs and I non-expected outputs $Y^{b}$ using $N$ inputs, and all inputs and outputs are required to be greater than or equal to 0 . The weight of observed values in each region is $\lambda_{p}^{b}$, and environmental technology is modeled. If $\Sigma \lambda^{p}=1$, it represents the production technology when the scale reward is variable (VRS), otherwise, it represents the constant scale reward (CRS). The SBM model for calculating GTFP in the $t$ period of a certain region under the constraint of resources and environment is as follows:

$$
\begin{gathered}
\rho_{0 t}^{*}=\min \frac{1-\frac{1}{3} \sum_{i=1}^{3} \frac{s_{i t}^{-}}{x_{i t 0}}}{1+\frac{1}{1+3}\left[\sum_{j=1}^{1} \frac{s_{j t}^{g}}{y_{j t 0}^{g}}+\sum_{r=1}^{3} \frac{s_{r t}^{b}}{y_{r t 0}^{b}}\right]} \\
\text { s.t. }\left\{\begin{array}{l}
\sum_{p=1}^{30} \lambda_{p}^{t} x_{i t p}+s_{i t}^{-}=x_{i t 0}, i=1,2,3 \\
\sum_{p=1}^{30} \lambda_{p}^{t} y_{r t p}^{b}+s_{r t}^{b}=y_{r t 0}^{b}, r=1,2,3 \\
\sum_{p=1}^{30} \lambda_{p}^{t} y_{j t p}^{g}-s_{j t}^{g}=y_{j t 0}^{g}, j=1 \\
s_{i t}^{-}>0, s_{j t}^{g}>0, s_{r t}^{b}>0, \lambda_{p}^{t}>0
\end{array}\right.
\end{gathered}
$$

...where, $s$ represents the slack of input and output. The objective function $p$ is strictly decreasing with respect to $s_{i t}^{-}, s_{j t}{ }^{\mathrm{g}}, s_{r t}^{b}$, between 0 and 1 . For a DMU, it is efficient if and only if $\rho^{*}=1$ and $s_{i t}{ }^{-}=s_{j t}{ }^{\mathrm{g}}=s_{r t}{ }^{b}=0$, otherwise it is inefficient. There is a need for improvement. $\rho^{*}$ represents green transformation performance in the region. If the value is small, the efficiency of green economy development is relatively lower.

Chung et al. applied the directional distance function containing bad output to the Malmquist model and called the Malmquist-Luenberger productivity index [20]. According to the method proposed by Chung, the $M L$ index of GTFP from period $t$ to period $t+1$ can be obtained as follows:

$$
\begin{aligned}
M L_{\mathrm{t}}^{t+1} & =\left\{\frac{1+\vec{D}_{0}^{t}\left(x^{t}, y^{t}, b^{t} ; g^{t}\right)}{1+\vec{D}_{0}^{t}\left(x^{t+1}, y^{t+1}, b^{t+1} ; g^{t+1}\right)}\right. \\
& \left.\times \frac{1+\vec{D}_{0}^{t+1}\left(x^{t}, y^{t}, b^{t} ; g^{t}\right)}{1+\vec{D}_{0}^{t+1}\left(x^{t+1}, y^{t+1}, b^{t+1} ; g^{t+1}\right)}\right\}^{\frac{1}{2}}
\end{aligned}
$$

In Eq. (2), $M L$ index represents the change of GTFP from period $t$ to period $t+1$ under a certain technical level. Based on the calculation of the four distance functions in Eq. (2), $M L$ index can be decomposed into $T E C H$ (technical progress) index and EFFCH (technical efficiency) index. The equations are as follows:

$$
\begin{gathered}
\text { EFFCH }_{t}^{t+1}=\frac{1+\vec{D}_{0}^{t+1}\left(x^{t}, y^{t}, b^{t} ; g^{t}\right)}{1+\vec{D}_{0}^{t+1}\left(x^{t+1}, y^{t+1}, b^{t+1} ; g^{t+1}\right)} \\
\text { TECH }_{t}^{t+1}=\left\{\frac{1+\vec{D}_{0}^{t+1}\left(x^{t}, y^{t}, b^{t} ; g^{t}\right)}{1+\vec{D}_{0}^{t}\left(x^{t}, y^{t}, b^{t} ; g^{t}\right)}\right. \\
\left.\times \frac{1+\vec{D}_{0}^{t+1}\left(x^{t+1}, y^{t+1}, b^{t+1} ; g^{t+1}\right)}{1+\vec{D}_{0}^{t}\left(x^{t+1}, y^{t+1}, b^{t+1} ; g^{t+1}\right)}\right\}^{\frac{1}{2}}
\end{gathered}
$$

$M L>1$ indicates that the GTFP of this region has increased, while $M L<1$ indicates that GTFP of this region has decreased. $E F F C H>1$ and $T E C H>1$ indicate the improvement of technical efficiency and cuttingedge technology progress in this area. On the contrary, $E F F C H<1$ and $T E C H<1$ indicate the deterioration of technical efficiency and backward cutting-edge technology in this area.

\section{Inputs and Outputs of the Evaluation Model}

Unlike traditional productivity evaluation, GTFP takes into account both resource inputs and undesired outputs. Among them, industrial wastewater, industrial $\mathrm{SO}_{2}$ and industrial smoke and dust are important sources of environmental pollution in China, and they account for a large proportion. Therefore, these three pollutants are selected as non-expected outputs.

During the research period from 2000 to 2017, 30 inland provinces are selected as the research samples. Due to the lack of a large number of statistical data in Tibet autonomous region, it is not included in the study scope. Hong Kong, Macau and Taiwan are also excluded because of their different statistical profiles. The indicators used to calculate GTFP include capital, labor, energy, GDP, industrial wastewater, industrial $\mathrm{SO}_{2}$ and industrial smoke and dust emissions. The original data are mainly from China statistical yearbook, China energy statistical yearbook and China urban statistical yearbook. Details of input-output variables are shown in Table 1. 
Table 1. Input and output variables and data description.

\begin{tabular}{|c|c|c|}
\hline Types & Variables & Index measurement and description \\
\hline \multirow{3}{*}{ Input } & Labor & The total number of employees at the end of the year \\
\hline & Capital & $\begin{array}{l}\text { The "perpetual inventory method" was adopted to estimate the capital stock } \\
\text { data of provinces. Taking the year } 2000 \text { as the base period, the capital stock and } \\
\text { depreciation rate of the base period were calculated by Zhang et al [40]. }\end{array}$ \\
\hline & Energy consumption & The total energy consumption of each province \\
\hline Desirable output & Economic development & Provincial real GDP at constant prices in 2000 \\
\hline \multirow[t]{3}{*}{ Undesirable output } & Industrial smoke and dust & $\begin{array}{l}\text { Industrial smoke and dust emissions of the province. Before 2011, the statistical } \\
\text { caliber was soot emission. The data before } 2011 \text { in this research used the sum } \\
\text { of industrial soot emission and industrial dust emission. After 2011, statistical } \\
\text { caliber was adopted to change the emission of industrial smoke and dust. }\end{array}$ \\
\hline & Industrial $\mathrm{SO}_{2}$ & Total industrial $\mathrm{SO}_{2}$ emissions in the province \\
\hline & Industrial wastewater & Total amount of industrial wastewater discharged in the province \\
\hline
\end{tabular}

\section{Model Calculation Results and Analysis}

According to SBM model and $M L$ productivity index method, based on input-output data of 30 provinces in China from 2001 to 2017, ML index and its decomposition of 30 provinces in China are obtained.

Fig. 1 shows the geometric mean values of $M L$, $E F F C H$, and TECH indexes of 30 provinces from 2001 to 2017. (1) Except for 2004-2005, the annual mean value of $M L$ index in other years is greater than 1 . And from 2001 to 2014, $M L$ index shows a downward trend of fluctuation. From 2014 to 2016, the index begins to show an upward trend. This shows that the efficiency of China's green economy was in a low state before 2014. In 2014, China entered the "new normal" of economic development. The economy changes from high-speed growth to high-quality growth, and GTFP begins to increase gradually. On the whole, $M L$ index increases slightly with an annual growth rate of $0.24 \%$, which indicates that China's green transformation performances are slowly increasing. (2) From the perspective of driving source of GTFP, the mean of

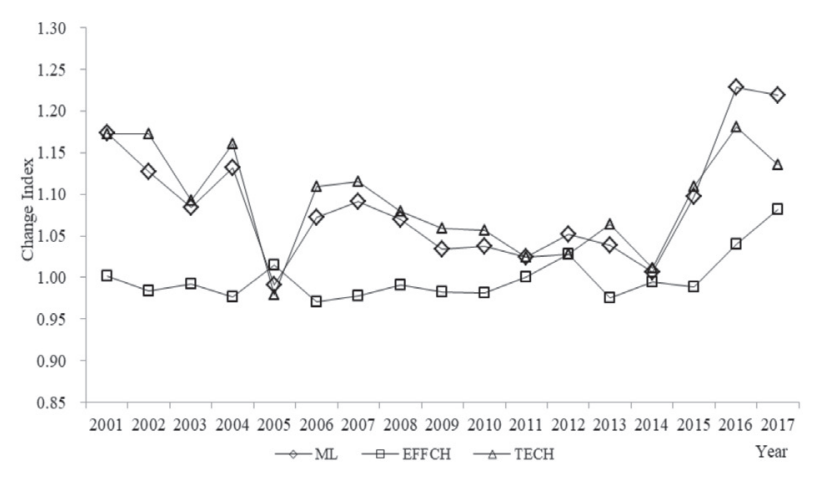

Fig. 1. ML index and its decomposition of 30 provinces in 2000-2017. The index corresponding to each year on the horizontal axis is the annual interval between the current year and the previous year. For example, the index corresponding to 2001 is the index value between 2000 and 2001 .
$E F F C H$ index in most years is less than or equal to 1 , which indicates that technical efficiency in China doesn't improve significantly during the study period. Technical efficiency has a negative impact on the annual growth of China's GTFPS. However, except for 2004-2005, the TECH index has an average value of more than 1 in all other years, which indicates that technical progress plays a key role in promoting the growth of Chinese green economic efficiency. Currently, China still has a lot of room for improvement in technical efficiency. To sum up, technical progress is the most contributor source to GTFP growth and technical efficiency is in the second order.

The $M L$ index calculated by Malmquist-Luenberger index method represents the growth rate of regional GTFP. As can be seen from Table 2, there are significant differences in GTFP among the 30 provinces in China, which are mainly divided into two types. (1) The first is green development progress type, that is, the $M L$ indexes are greater than 1 , and GTFPS show an overall growth trend, including 28 provinces such as Beijing, Tianjin, Zhejiang, etc. The balance between environmental protection and economic development has been achieved. The $M L$ and $T E C H$ mean values of Zhejiang province are both at a high level $(1.221,1.223)$, and the $E F F C H$ mean value is 0.999 . Technical progress makes the GTFP of Zhejiang province approach the production frontier. However, with the increasing input scale of traditional resources, the marginal productivity of resources is reduced, which leads to the decline of its technical efficiency. Technical progress indexes of 13 provinces, such as Hebei, Shanxi, Liaoning, are greater than 1. Technical efficiency indexes are less than 1 , which indicate that green economy development mainly relies on the growth effect brought by technical progress, while the technical efficiency is in second order. Technical progress indexes and technical efficiency indexes of 15 provinces such as Beijing, Tianjin and Shanghai are all greater than 1, which show that green developments of these provinces are 
Table 2. The mean value and decomposition of GTFP index of each province in 2001-2017.

\begin{tabular}{|c|c|c|c|c|c|c|c|}
\hline Province & ML & EFFCH & TECH & Province & ML & EFFCH & TECH \\
\hline Beijing & 1.131 & 1.000 & 1.131 & Henan & 1.204 & 1.011 & 1.182 \\
\hline Tianjin & 1.078 & 1.000 & 1.078 & Hubei & 1.174 & 1.066 & 1.111 \\
\hline Hebei & 1.128 & 0.993 & 1.133 & Hunan & 1.184 & 0.964 & 1.246 \\
\hline Shanxi & 1.022 & 0.984 & 1.038 & Guangdong & 1.046 & 1.000 & 1.046 \\
\hline $\begin{array}{c}\text { Inner } \\
\text { Mongolia }\end{array}$ & 1.127 & 0.973 & 1.162 & Guangxi & 1.043 & 0.989 & 1.054 \\
\hline Liaoning & 1.117 & 0.956 & 1.178 & Hainan & 1.014 & 1.000 & 1.014 \\
\hline Jilin & 1.058 & 0.991 & 1.069 & Chongqing & 1.067 & 1.021 & 1.046 \\
\hline Heilongjiang & 1.108 & 1.024 & 1.081 & Sichuan & 1.104 & 1.010 & 1.094 \\
\hline Shanghai & 1.066 & 1.000 & 1.066 & Guizhou & 1.037 & 1.003 & 1.034 \\
\hline Jiangsu & 1.133 & 1.005 & 1.134 & Yunnan & 1.038 & 0.985 & 1.054 \\
\hline Zhejiang & 1.221 & 0.999 & 1.223 & Shaanxi & 1.035 & 0.994 & 1.042 \\
\hline Anhui & 1.120 & 0.987 & 1.136 & Gansu & 1.031 & 1.000 & 1.032 \\
\hline Fujian & 1.131 & 1.000 & 1.131 & Qinghai & 0.973 & 1.000 & 0.973 \\
\hline Jiangxi & 1.072 & 0.959 & 1.138 & Ningxia & 0.849 & 1.045 & 0.817 \\
\hline Shandong & 1.271 & 1.040 & 1.242 & Xinjiang & 1.027 & 0.976 & 1.055 \\
\hline
\end{tabular}

driven by growth effect of technical progress and catchup effect of technical efficiency. (2) The second is the green development recession type, that is, the GTFPS are less than 1 , and green productivity generally shows a declining trend. Technical progress indexes of the two provinces of Ningxia and Qinghai are less than 1, which indicate that the two provinces have low technological innovation ability and low quality of human resources, resulting in low technical progress index. Therefore, the low level of technical progress leads to lower GTFP in these two provinces. Comprehensive analysis shows that the main reason of restricting the growth of GTFP in most provinces is low technical efficiency. In conclusion, all provinces should attach great importance to the improvement of technical efficiency while promoting technical progress.

From the perspective of mainland China, China's GTFP indexes rise from 1.172 in 2001 to 1.219 in 2017, showing a slowly rising trend. In terms of different regions, as shown in Fig. 2, the GTFP indexes in western region are always in a low state from 2001 to 2017, and they are below 1 for a long period. In the long run, it is a slow process of rising, but in some years it also shows a downward trend. The variation trend of GTFP of central region is similar to western region, but the index values are slightly higher than western region. Eastern region has the highest index value, and the curve is above the national average of GTFP. From 2001 to 2017, GTFP of eastern region is in a state of first decline and then slow rise. Before 2005, it is in a state of first decline and then rise. The gap between central and western regions increases. The GTFP indexes in eastern and central regions begin to rise sharply in 2014 and decline slightly in 2016-2017, while the western region remains in a depressed state. It can be seen that the high-quality economic developments in eastern and central China are in a good trend during research periods, while economic development and environmental protection in western region are not balanced enough.

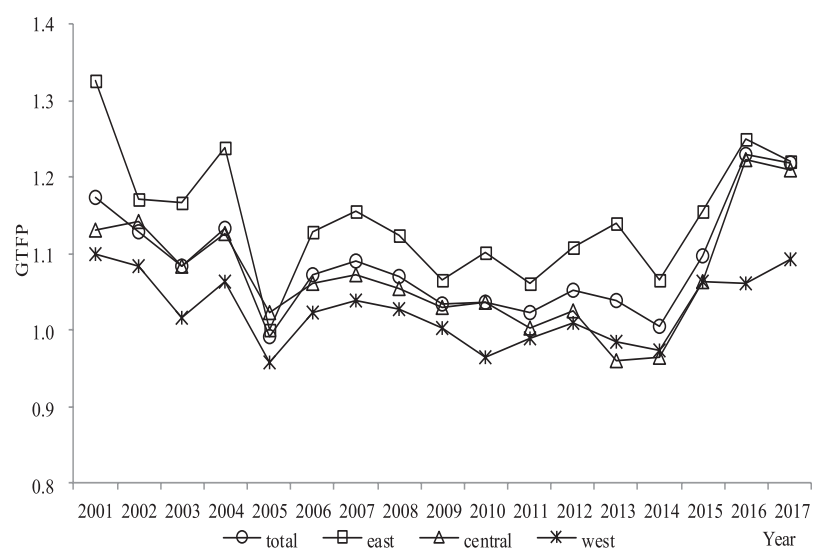

Fig. 2. Sub-regional and China's GTFP dynamic trends in 2001-2017.

Eastern China includes Beijing, Guangdong, Hebei, Jiangsu, Liaoning, Shanghai, Tianjin, Zhejiang, Fujian, Shandong and Hainan provinces. Central China includes Hubei, Heilongjiang, Shanxi, Anhui, Jiangxi, Jilin, Hunan and Henan provinces and western region are Shaanxi, Qinghai, Xinjiang, Yunnan, Gansu, Sichuan, Inner Mongolia, Guizhou, Guangxi and Ningxia provinces. 


\section{Dynamic Evolution Characteristics Analysis Based on Kernel Density}

In order to analyze the dynamic variation of GTFP in Chinese provinces, the kernel density estimation method is used. The method is a typical non-parametric estimation method, which takes GTFP as a continuous state and studies the distribution of green transformation performance in Chinese province. Thus, it can directly reflect the distribution and evolution trend of GTFP. If the probability density function of variable distribution has the shape of "one-peak", then the distribution of GTFP in the province tends to converge to the same equilibrium point. However, if variable distribution of the probability density function appears "bimodal" or even "multi-peak", it indicates that the difference distribution of GTFP in the provincial area converges to the two equilibrium points of high level and low level or even more equilibrium points.

In this research, the widely accepted Gaussian kernel expansion estimation is used to obtain the kernel density distribution of GTFP in the four representative years by using Stata13.0. The kernel density functions of 30 provinces in 2001,2005, 2010 and 2017 are estimated. The reason for choosing these four years is that 2001 and 2017 are the beginning and end of the sample period, and 2001-2005, 2005-2010, 2010-2015 are the representative years of the national "the tenth Five-Year Plan", "the eleventh Five-Year Plan" and "the twelfth Five-Year Plan" respectively, with greater research significance. The horizontal axis represents the interprovincial GTFPS index and the vertical axis represents the nuclear density. According to the shape of kernel density curve during the sample period, dynamic evolution characteristics of regional green transformation performances can be determined.

Fig. 3 shows the dynamic evolution characteristics of GTFP distribution in China's provinces. The following conclusions can be seen from the figure: (1) From 2001 to 2017, the kernel density curves of provincial GTFPs have an obvious "one-peak", which suggests that the provincial green transformation performances tend to converge at the same equilibrium point. On the right side of the curve, there is a trailing phenomenon, which indicates that although the overall GTFP level is not high, there are still some provinces whose green transformation performances are higher than national average. (2) From 2001 to 2005, the peak point moves to the left, and the GTFP index corresponding to the peak decreases. The reason may be that most provinces only pay attention to high speed of economic development and ignore environmental protection during this period, resulting in the decrease of GTFP. During the two periods from 2005 to 2010 and from 2010 to 2017, the peak point shifts to the right year by year, with little change in the speed. This shows that from the beginning of the $11^{\text {th }}$ Five-Year Plan, most of Chinese provinces begin to attach importance to high-quality development of economy, coordinating the relationship between environmental protection and economic growth. The manifestation is the right shift of the crest, that is, the improvement of interprovincial GTFPs. On the whole, GTFPS decrease first and then increase dynamically. (3) From 2001 to 2005 and from 2005 to 2010, the peak of kernel density distribution curve keeps increasing, which indicates that the concentration degrees of GTFPS in each province increase year by year, and regional differences decrease gradually. However, from 2010 to 2017 , the peak point decreases significantly, which shows that concentration degrees decrease, and regional differences increase. The reason may be that during the $12^{\text {th }}$ Five-Year Plan period, developed provinces achieve a win-win situation of environmental and economic development through "management emission reduction" and "natural emission reduction". But extensive growth model of "high energy consumption and high emissions"

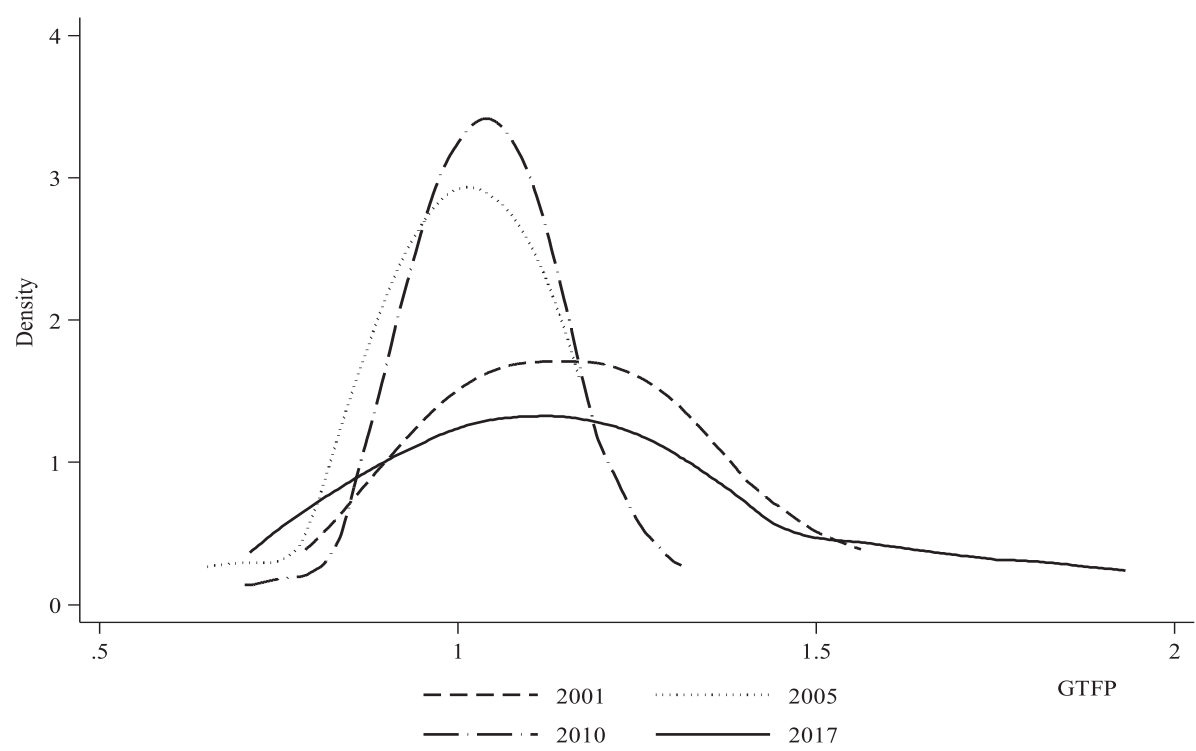

Fig. 3. A comprehensive map of kernel density distribution of GTFP in typical years. 
in economically backward provinces eventually leads to "double deterioration" of environmental and economic development. In conclusion, the kernel density curves of GTFP in China have an obvious "one-peak", which indicates that Chinese provincial green transformation performances converge to the same convergence point. Its peak point moves to the right and downward directions from the horizontal and vertical axis. Regional heterogeneity characters are becoming more and more obvious which should be considered as an important influential factor.

\section{Key Influence Factors of the GTFPs}

\section{Dynamic Panel Data Econometric Model}

In this research, 30 provinces in China are taken as research objects, and panel data from 2001 to 2017 are used for empirical analysis. Seven explanatory variables are set, including economic agglomeration, energy consumption, technical progress, environmental regulation, economic development level, labor quality and factor structure. GTFPs evaluated in section 3 are taken as the explained variable. Because of inertia or partial adjustment, an individual's current behavior depends on past behavior. Therefore, the dynamic panel model is established by including the lag term of the explained variable in the explanatory variable. Where, the SYS-GMM estimation method can effectively solve the endogenous problem of explanatory variables to some extent by introducing instrumental variables into the estimation equation. So the SYS-GMM dynamic panel of the model is set as follows:

$$
\begin{gathered}
\ln \text { TTFP }_{i t}=\mu_{i}+\beta_{0} \ln G T F P_{i t-1}+\beta_{1} \ln \mathrm{AGG}_{i t} \\
+\theta_{1} \ln E \mathrm{~S}_{i t}+\theta_{2} \ln R D_{i t}+\theta_{3} \ln E R_{i t} \\
+\theta_{4} \ln E L_{i t}+\theta_{5} \ln J Y_{i t}+\theta_{6} \ln K L_{i t}+\varepsilon_{i t}
\end{gathered}
$$

...where $i$ represents the province; $t$ is the year; GTFP represents green transformation performance; $A G G$ is economic agglomeration; ES is energy consumption; $\mathrm{RD}$ is the technical progress; ER is environmental regulation; EL is economic development level; JY is the labor quality; KL is the factor structure; $\mu_{i}$ is individual effect; $\varepsilon_{i t}$ is the random disturbance term.

\section{Variable Selection and Description}

Provincial green transformation performances are chosen as the explained variable in this econometric model. In this section, GTFP is used to reveal green transformation performance. Provincial GTFPS concern all aspects of the "economy-environment-resource" integrated system, so there are many driving factors. This research summarize existing literature and connotation of GTFP, which select the driving factors by considering five aspects: economic development level (such as economic agglomeration and GDP per capita), technological level factors (such as technical progress and the labor quality), industrial structure factors (such as the factor structure), energy consumption factors and government environmental regulation.

More specifically, they are as follows:

(1) Economic agglomeration. It is a key variable which is often used in region economics to estimate the concentration of economic activities in space, which reflects economic intensity of a region. Economic agglomeration promotes economic development through the spillover effect of knowledge and relatively skilled labor market. These are manifested as the scale effect of agglomeration. However, when economic agglomeration develops to a certain degree, environmental pollution and congested public infrastructure will inhibit economic development, and they are manifested as the congestion effect of agglomeration. It is revealed by labor quantity per area. (2) Energy consumption. For a long time, Chinese economy is given priority to with rough type development. This rapid development has consumed a large amount of natural resources and discharged many pollutants into the environment, adversely affecting green development. In this research, ten thousand yuan GDP energy consumption is chosen to represent the energy consumption factor. (3) Technical progress. Technical progress and innovation are the fundamental driving force for green development, which are conducive to improving factor utilization rate, promoting intensive and recycling utilization of resources. Therefore, this research selects the proportion of internal expenditure of research and experimental development (R\&D) funds in regional GDP to measure the level of technical progress. (4) Environmental regulation. Government environmental regulation will internalize the external cost of environment, which will reduce the competitiveness of enterprises, and then lead to the decline of GTFP. On another dimension, it will enhance the public's environmental awareness, and form a good atmosphere of attaching importance to environmental quality. Therefore, it remains to be proved whether environment regulation has a position or negative impact on green economic efficiency. This research chooses the proportion of pollution control investment in the GDP of each province to measure the environmental regulation factor. (5) Economic development level. The rapid economic growth provides the material basis for technological innovation and pollution control. This research uses per capita GDP to measure the economic development level of each region. (6) Labor quality. Human capital is an important force to promote GTFP. In this research, the average years of schooling in each region is used to measure labor quality. (7) Factor structure. It is represented by the capital-labor ratio. Capital is estimated according to the perpetual inventory method, and labor is expressed by the total number of employees in each region at the end of the year. The rising capital-labor ratio means the deepening of capital, and it remains to be verified 
Table 3. Descriptive statistics of variables.

\begin{tabular}{|c|c|c|c|c|c|c|}
\hline Variables & Definition & Observation & Min & Max & Mean & Std. Dev. \\
\hline $\ln G T F P$ & Green TFP & 510 & -3.3978 & 3.9141 & 0.6458 & 0.8415 \\
\hline $\ln \mathrm{AGG}$ & Economic agglomeration & 510 & 1.3749 & 7.6865 & 4.827 & 1.3147 \\
\hline $\operatorname{lnES}$ & Energy consumption & 510 & -0.6428 & 7.1862 & 0.4201 & 0.7083 \\
\hline $\operatorname{lnRD}$ & Technical progress & 510 & -1.9205 & 2.0025 & 0.0486 & 0.6817 \\
\hline $\operatorname{lnER}$ & Environmental regulation & 510 & -1.204 & 1.4446 & 0.1579 & 0.4662 \\
\hline $\operatorname{lnEL}$ & GDP per capita & 510 & -1.2395 & 2.5572 & 0.8757 & 0.8106 \\
\hline $\ln J Y$ & Labor quality & 510 & 1.7864 & 2.6821 & 2.1462 & 0.1298 \\
\hline $\operatorname{lnKL}$ & Factor structure & 510 & 0.8204 & 4.0193 & 2.3376 & 0.6929 \\
\hline
\end{tabular}

whether the deepening of capital has a positive or negative impact on GTFP.

The empirical samples of this research are the balance panel data formed by 30 provinces in mainland China from 2000 to 2017. The original data are mainly from China statistical yearbook and China environmental statistical yearbook. Table 3 shows the descriptive statistics of each variable.

\section{Statistical Tests and Estimation Results}

Firstly, to avoid pseudo-regression, unit root test is performed on the variables. Secondly, Hausman test is carried out to determine that which model should be adopted. Finally, F test, determination coefficient test and logarithmic likelihood function test are performed to select specific form of the model.

The unit root test is performed before analysis. The LLC and ADF-Fisher tests are performed for the explained variables and explanatory variables, respectively. The results show that all variables pass LLC and ADF-Fisher tests at a significance level of $10 \%$. As shown in Table 4, all influencing factors of Chinese provincial GTFPs are zero order single integral, so the next empirical analysis can be carried out.
Before constructing the traditional panel regression model, the Hausman test is used to determine the choice of fixed effect model or random effect model. Hausman test results are shown in Table 5. The Hausman test statistical value is 22.10 , which passes the significance level of $1 \%$. Therefore, the null hypothesis is rejected and the fixed effect model is selected for analysis.

Then, the concrete form of fixed effect model will be determined. There are four models: mixed effect, individual fixed effect, period fixed effect and two-way fixed effect. Three kinds of tests are mainly adopted, namely $\mathrm{F}$ test, determination coefficient test and Loglikelihood function test. Table 6 shows specific results of three tests. First, F statistics of above four models are all significant at the confidence level of $1 \%$, which suggests that the fitting effects of four models are better. Second, $\mathrm{R}^{2}$ values of individual fixed effect model and two-way fixed effect model are 0.8105 and 0.8372 , respectively, which are significantly higher than the other two models. Third, Log-likelihood variable values of individual and two-way fixed effect models are -172.6508 and -211.3839 , respectively, which are obviously higher than mixed effect model and period fixed effect model. Therefore, the individual fixed effect model and the two-way fixed effect model are more

Table 4. Panel data stationarity test of driving factors of GTFP.

\begin{tabular}{|c|c|c|c|c|c|}
\hline \multirow{2}{*}{ Variables } & \multicolumn{2}{|c|}{ LLC } & \multicolumn{2}{|c|}{ ADF-Fisher } & \multirow{2}{*}{ Conclusion } \\
\hline & Statistical value & $P$ value & Statistical value & $P$ value & \\
\hline $\ln G T F P$ & -12.6854 & 0.000 & 183.6770 & 0.000 & $\mathrm{I}(0)$ \\
\hline $\ln A G G$ & -4.7344 & 0.000 & 138.7604 & 0.000 & $\mathrm{I}(0)$ \\
\hline $\operatorname{lnES}$ & -13.3226 & 0.000 & 100.4657 & 0.000 & $\mathrm{I}(0)$ \\
\hline $\ln R D$ & -6.3870 & 0.000 & 170.7935 & 0.000 & $\mathrm{I}(0)$ \\
\hline $\operatorname{lnER}$ & -6.3254 & 0.000 & 137.9662 & 0.000 & $\mathrm{I}(0)$ \\
\hline $\operatorname{lnEL}$ & -3.0458 & 0.001 & 146.3141 & 0.000 & $\mathrm{I}(0)$ \\
\hline $\ln J Y$ & -10.2931 & 0.000 & 162.9379 & 0.000 & $\mathrm{I}(0)$ \\
\hline $\operatorname{lnKL}$ & -1.3931 & 0.081 & 145.4227 & 0.000 & $\mathrm{I}(0)$ \\
\hline
\end{tabular}


Table 5. Hausman estimation results of traditional panel data regression model.

\begin{tabular}{|c|c|c|c|}
\hline Test Summary & Chi-Sq.Statistic & Chi-Sq.d.f. & Prob. \\
\hline Cross-section random & 22.10 & 8 & 0.0086 \\
\hline
\end{tabular}

Table 6 . The test statistics of four model forms under ordinary panel model.

\begin{tabular}{|c|c|c|c|c|}
\hline Variables & Mixed effects & Individual fixed effect & Period fixed effect & Two-way fixed effects \\
\hline F value & $45.0859 * * *$ & $56.2249 * * *$ & $16.4031^{* * *}$ & $45.2191 * * *$ \\
\hline $\mathrm{R}^{2}$ & 0.3860 & 0.8105 & 0.4370 & 0.8372 \\
\hline Log-likelihood & -511.2676 & -172.6508 & -489.1474 & -211.3839 \\
\hline
\end{tabular}

ideal than the other two. There are little differences between individual fixed effect model and two-way fixed effect model fit values with $\mathrm{R}^{2}$ and Log-likelihood variable values. Therefore, this research adopted an individual fixed effect to set the model.

For the above model, OLS method and SYS-GMM method are respectively used for parameter estimation. Table 7 is the specific results obtained. According to OLS regression results, although $\mathrm{R}^{2}$ value is 0.437 , most regression coefficients of each variable show a significant level. The coefficient symbol is consistent with the expectation. Overall, the model is robust. According to SYS-GMM regression results, Sargan test results indicate that the selection of instrumental variables is effective. Coefficient joint test suggests that the model as a whole is highly significant. Residual sequence correlation test proves that sequence correlation doesn't exist. The lag period of GTFP is highly positive and significant, which indicates that there is an obvious "transfer effect" between the current GTFP and earlier period. This means that GTFP accumulated in the early stage will form a demonstration effect and a virtuous circle, forming a continuous "green driving effect". In summary, it can be seen that the parameter estimation results obtained by the two methods are significantly different. Among them, the significance of the three variables of environmental regulation, technical progress and labor quality has changed. The positive and negative signs of estimated parameters of economic agglomeration, economic development level and factor structure have changed. Economic agglomeration and factor structure change from negative effect to positive effect, and economic development level change from positive effect to negative effect. Overall, SYS-GMM method is more accurate than OLS method.

According to parameter estimation of model (2) in Table 7, economic agglomeration and factor structure have a significant positive impact on GTFP in the current period. Energy consumption, environmental regulation and economic development level significantly inhibit GTFP. Technical progress and labor quality are not significant. Next, focus on the regression results of each explanatory variable in turn. (1) The estimated parameter of economic agglomeration variable is 0.1702 , which shows that economic agglomeration level has a significant promotion effect on GTFP growth at this stage. When the degree of

Table 7. Estimation results of model parameters (under individual fixed effect)

\begin{tabular}{|c|c|c|}
\hline \multirow{2}{*}{ Variables } & OLS & SYS-GMM \\
\hline & Model(1) & Model(2) \\
\hline $\ln G T F P(-1)$ & - & $\begin{array}{c}1.0157 * * * \\
(25.25)\end{array}$ \\
\hline $\ln A G G$ & $\begin{array}{c}-0.1036^{* * *} \\
(-2.80)\end{array}$ & $\begin{array}{c}0.1702 * * * \\
(2.96)\end{array}$ \\
\hline $\operatorname{lnES}$ & $\begin{array}{c}-0.3031 * * * \\
(-3.92)\end{array}$ & $\begin{array}{c}-0.0277 * * \\
(-2.95)\end{array}$ \\
\hline $\operatorname{lnER}$ & $\begin{array}{c}-0.0705 \\
(-0.92)\end{array}$ & $\begin{array}{c}-0.0681 * * * \\
(-3.49)\end{array}$ \\
\hline $\ln R D$ & $\begin{array}{c}0.1266^{*} \\
(1.89)\end{array}$ & $\begin{array}{l}0.1165 \\
(-1.14)\end{array}$ \\
\hline $\ln E L$ & $\begin{array}{c}1.5592 * * * \\
(7.39)\end{array}$ & $\begin{array}{c}-0.2682 * * * \\
(-3.89)\end{array}$ \\
\hline $\ln J Y$ & $\begin{array}{c}1.2078 * * \\
(2.52)\end{array}$ & $\begin{array}{c}0.3365 \\
(1.49)\end{array}$ \\
\hline $\operatorname{lnKL}$ & $\begin{array}{c}-1.6041 * * * \\
(-9.32)\end{array}$ & $\begin{array}{c}0.3231 * * * \\
(2.97)\end{array}$ \\
\hline Constant term & $\begin{array}{l}1.0702 \\
(1.15)\end{array}$ & $\begin{array}{c}-1.9841^{* * *} \\
(-3.29)\end{array}$ \\
\hline F test & 0.000 & - \\
\hline R-squared & 0.437 & - \\
\hline Wald-test-p & - & 0.000 \\
\hline Sargan test & - & 0.715 \\
\hline $\mathrm{AR}(1)$ & - & 0.007 \\
\hline $\mathrm{AR}(2)$ & - & 0.405 \\
\hline
\end{tabular}

"***", "**", and "**" represents the statistical significance level of $1 \%, 5 \%$ and $10 \%$ respectively. Sargan statistic tests whether the moment condition is over-identified. Wald is the coefficient joint significance test, and AR (2) is the residual second-order sequence correlation test. 
economic agglomeration is within a reasonable range, technology spillover effect of enterprises and reduction of information communication costs will increase economic production efficiency of the region. At the same time, the improvement of energy efficiency will reduce the emission of pollutants. Therefore, positive externalities of economic agglomeration promote the growth of GTFP. (2) The estimated coefficient of energy consumption is -0.0277 . It shows that during the sample period, energy consumption factor has inhibited GTFP growth in Chinese provincial areas. As is known to all, both economic growth and productivity improvement are accompanied by resource and energy consumption. A negative coefficient indicates that economic growth caused by energy consumption cannot offset the negative impact on the environment. (3) The impact of environmental regulation on GTFP is negative and significant. The reason may be that most of environmental policies are based on emission restraint and pollution control, with the ultimate goal of balancing environmental pollution and economic performance. Therefore, if environmental regulations are poorly designed, they are likely to have the opposite effect on GTFP promotion. (4) Economic development level has a negative and significant impact on GTFP. For a long time, China's economic growth has been heavily dependent on energy consumption, resulting in excessive consumption of resources and serious environmental pollution. The coordination of economic development and ecological environmental protection has not been realized. (5) The influence of factor structure estimation parameters on GTFP is positive. The increasing of capital-labor ratio is beneficial to the improvement of the green economy efficiency, and the deepening of capital makes the economic structure gradually transform from labor-intensive to capitalintensive. The technology level of capital intensive enterprises is often higher, and the improvement of technology level largely offset its negative impact on resources and environment. (6) The estimated parameters of technical progress and labor quality are both positive and insignificant. The reason may be that efficiency of R\&D investment in China is relatively low at the present stage, and spillover effect of knowledge and technology does not significantly promote green transformation performance.

\section{Regional Sample Regression Results}

Taking into account the different degrees of openness and economic development level in different regions, this research divides the whole sample into eastern region and central and western regions for empirical analysis. Table 8 reports SYS-GMM estimates by region.

With Table 8, there are no significantly differences between the two estimation results, in compared with Table 7. It reveals that regression results for parameters are robust. The following is the analysis of the results
Table 8. Regional sample regression results (under individual fixed effect).

\begin{tabular}{|c|c|c|}
\hline Variables & Eastern region & $\begin{array}{l}\text { Central and west- } \\
\text { ern regions }\end{array}$ \\
\hline $\ln G T F P(-1)$ & $\begin{array}{c}1.0372 * * \\
(2.29)\end{array}$ & $\begin{array}{c}1.0561 * * * \\
(15.36)\end{array}$ \\
\hline $\ln A G G$ & $\begin{array}{c}0.6715^{* * * *} \\
(-4.65)\end{array}$ & $\begin{array}{c}-0.7782 \\
(-0.83)\end{array}$ \\
\hline $\ln E S$ & $\begin{array}{c}-0.2398 * * \\
(-2.30)\end{array}$ & $\begin{array}{c}-0.0398 * * * \\
(-3.57)\end{array}$ \\
\hline $\operatorname{lnER}$ & $\begin{array}{c}-0.0601 \\
(-0.70)\end{array}$ & $\begin{array}{c}-0.0708 \\
(-1.21)\end{array}$ \\
\hline $\operatorname{lnRD}$ & $\begin{array}{l}0.2688 \\
(1.64)\end{array}$ & $\begin{array}{c}-0.2251 * * * \\
(-3.81)\end{array}$ \\
\hline $\ln E L$ & $\begin{array}{l}0.6859^{* * * *} \\
(3.65)\end{array}$ & $\begin{array}{c}-0.2357^{* *} \\
(-2.53)\end{array}$ \\
\hline $\ln J Y$ & $\begin{array}{c}1.3578^{* *} \\
(2.36)\end{array}$ & $\begin{array}{c}0.3693^{*} \\
(1.76)\end{array}$ \\
\hline $\ln K L$ & $\begin{array}{l}0.1431 \\
(0.67)\end{array}$ & $\begin{array}{c}0.3819^{* * * *} \\
(3.44)\end{array}$ \\
\hline Constant term & $\begin{array}{c}6.2315^{* * * *} \\
(2.68)\end{array}$ & $\begin{array}{l}1.8749 \\
(0.49)\end{array}$ \\
\hline Wald-test-p & 0.000 & 0.000 \\
\hline Sargan test & 0.681 & 0.997 \\
\hline $\operatorname{AR}(1)$ & 0.027 & 0.029 \\
\hline $\mathrm{AR}(2)$ & 0.128 & 0.676 \\
\hline
\end{tabular}

after regional regression:

(1) The influence of energy consumption, environmental regulation, labor quality and factor structure on GTFP is consistent with the overall analysis. Among them, the labor quality significantly promotes the regional GTFP growth, and the coefficient of the eastern region is obviously greater than that of the central and western regions. The reason may be that the education level of the eastern region is obviously better than that of other regions, and the spillover effect of knowledge and technology has obviously promoted the green transformation and development of the eastern region. The factor structure has a positive and significant effect in the central and western regions. The deepening of capital in the central and western regions makes economic structure gradually transform to capital-intensive, and capital-intensive enterprises tend to have higher technical level, thus promoting the promotion of regional GTFP.

(2) Economic agglomeration has a significantly positive impact on GTFP in eastern region, but not in central and western regions. Probably as the agglomeration level in eastern region is in a promotion stage, and economic agglomeration brings about the improvement of green economic efficiency. However, the agglomeration degree of central and western regions is not enough to effectively improve GTFP. Technical level promotes the green development in eastern region, 
but has no significant effect on GTFP in central and western regions. The possible reason is that eastern region has a higher investment in $R \& D$ funds and a higher rate of return on $R \& D$ investment, which strongly promotes the green economy development in the region. Economic development level in eastern shows a significant role in promoting, but it's negative for central and western regions. The reason may be that, at present, economic development level of eastern coastal areas is relatively high. A large amount of highquality human capital is gathered, which is conducive to technology spillover. Thus, it further promotes green transformation performance of eastern region. However, central and western regions are still in the stage of extensive development, and economic development is accompanied by excessive energy consumption and a large number of pollutant emissions. Therefore, the higher economic development level doesn't bring about the improvement of GTFP level in the central and western regions.

\section{Main Conclusions and Policy Implications}

Firstly, bases on panel data of 30 provinces in China from 2001 to 2017, this research uses DEASBM model and $M L$ productivity index to calculate provincial GTFPs. Secondly, dynamic evolution of GTFP in Chinese province is analyzed by kernel density estimation. Finally, the driving factors of GTFP are studied by constructing SYS-GMM dynamic panel model. The main conclusions and policy implications are as follows.

\section{The Main Conclusions}

First, there is an increasing trend concerning provincial GTFPs in China during 2000-2017. They are dominated by technical progress and efficiency trends. Technical progress influences GTFP more than that technical efficiency. 30 mainland provinces are classified into two types based on their GTFP growths and they are green-growing type and green-declining type. Green-declining type contains two provinces and they are Ningxia and Qinghai provinces. The other 28 provinces are of green-growing type. Most Chinese provinces show slower GTFP growth rates during the years of 2000-2017. Inadequacy development of green economic transformation occurs obviously in China nowadays. How to push GTFPS growth is the most important direction for China when they realize their green development concept.

Second, green transformation performance growth in eastern and central China were more than that of western region. The kernel density curves of provincial GTFPs indicated that the distribution of China's provincial green transformation performances tended to converge to the same equilibrium point. Overall, the peak point moved to the right and downward directions from the horizontal and vertical axis. Regional heterogeneity characters were becoming more and more obvious which should be considered as important influential factor.

Third, the analysis of SYS-GMM dynamic panel model shows that economic agglomeration and factor structure can significantly promote the improvement of provincial green transformation performances. Energy consumption, environmental regulation and economic development level can inhibit the promotion of GTFP. The sub-regional regression results shows that economic agglomeration and technical progress have a positive effect on green economic efficiency in eastern region, but not in central and western regions. Economic development level of eastern region promotes the growth of GTFP, but the other regions are the opposite. At current stage, positive externalities of economic agglomeration are the key to promoting green transformation.

\section{Policy Implications}

Based on the main conclusions, such policy implications should be provided and they are as follows:

First, accelerating green technology innovation development is the most potential way to stimulate Chinese GTFP growth. Inadequacy development of green technology field is great significant in current stage during realizing high-quality development. Three important directions should be focused to accelerate green technology innovation. Increasing green R\&D funds inputs, green innovation-knowledge accumulation and clearing the patent transformation channels are the most important ways to help economic green development. They are as follows in details. On one side, promoting green knowledge, research and industrial production integration more in-depth should be paid more attention to. On the other side, more stimulating policies concerning green technology utilization should be supplied to industrial enterprises, especially to pollutant sectors. Thus, human capital and knowledge accumulation mechanisms in environmental technology shall obtain more opportunities to stimulate their cleaner productivity.

Second, proper spatial arrangement is another important direction to comprehensive acceleration China's GTFP. Regional differences among eastern, central and western regions' GTFPs of China are much obviously during their GTFPs during the research period. On one hand, differentiated regional development policies should be considered for the regions. For most eastern provinces, utilizing their $R \& D$ endowment advantages and guiding them to more environmentally friendly technology field are the key steps. The positive externalities of economic agglomeration should be fully exploited. In the process of agglomeration, the government should encourage the development of emerging green industries dominated by new energy technologies and environmental 
technologies. For central and western regions, how to release economic agglomeration potentials is more important to accelerate their GTFP growth. On the other hand, inter-regional cooperation in the process of green transformation is also important to stimulate whole GTFP of China. Coordination development such as Beijing-Tianjin-Hebei region, the Yangtze River Delta area and Yangtze River Economic Zone should be put in the first order to push green transformation performance and obtain such ' $1+1>2$ ' amplifying effects.

\section{Conflict of Interest}

The authors declare no conflict of interest.

\section{References}

1. MUNDACA L., MARKANDYA A. Assessing regional progress towards a 'Green Energy Economy'. Applied Energy, 179, 1372, 2016.

2. HERRERIAS M.J., JOYEUX R., GIRARDIN E. Shortand long-run causality between energy consumption and economic growth: evidence across regions in China. Applied Energy, 112, 1483, 2013.

3. YUAN W.H., LI J.C., MENG L., QIN X.N., QI X.X. Measuring the area green efficiency and the influencing factors in urban agglomeration. Journal of Cleaner Production, 241, 118092, 2019.

4. LI K., LIN B.Q. Economic growth model, structural transformation, and green productivity in China. Applied Energy, 187, 489, 2017.

5. FUJITA M., JACQUES-FRANCOIS T. Economics of Agglomeration: Cities, Industrial Location, and Regional Growth, Cambridge University Press, 2002.

6. BRÜLHART M., MATHYS N.A. Sectorial Agglomeration Economies in a Panel of European Regions. Regional Science and Urban Economics, 38 (4), 348, 2008.

7. BAUMONT C., ERTUR C., LE GALLO J. Spatial Analysis of Employment and Population Density: the Case of the Agglomeration of Dijon 1999. Geographical Analysis, 36 (2), 146, 2004.

8. CHEN Y. Agglomeration and Location of Foreign Direct Investment: The Case of China. China Economic Review, 20 (3), 549, 2009.

9. LIN H.L., LI H.Y., YANG C.H. Agglomeration and Productivity: Firm-level Evidence from China's Textile Industry. China Economic Review, 22 (3), 313, 2011.

10. HE W.J., ZHANG H.F., CHEN X.C., YAN J.J. An empirical study about population density, economic agglomeration and carbon emission state of Chinese provinces: based on the perspective of agglomeration economy effects, congestion effects and spatial effects. Nankai Economic Studies, 2, 207, 2019.

11. ZHANG K., WANG D.F. The interaction and spatial spillover between agglomeration and pollution. China Industrial Economics, 6, 70, 2014.

12. LI Y.G., ZHANG P. Have industrial agglomeration aggravated regional environmental pollution-Chinese provincial level empirical evidence. Journal of Huazhong University of Science and Technology (Social Science Edition), 27 (05), 97, 2013.
13. YANG R.F. Whether industrial agglomeration can reduce environmental pollution or not? China Population, Resources and Environment, 25 (02), 23, 2015.

14. KUMAN A., ASWIN A., GUPTA H. Evaluating green performance of the airports using hybrid BWM and VIKOR methodology. Tourism Management, 76, 103941, 2020.

15. HOU J., TEO T.S.H., ZHOU F.L., LIM M.K., CHEN H. Does industrial green transformation successfully facilitate a decrease in carbon intensity in China? An environmental regulation perspective. Journal of Cleaner Production, 184, 1060, 2018.

16. YIN S., LI B.Z., XING Z.Y. The governance mechanism of the building material industry (BMI) in transformation to green BMI: The perspective of green building. Science of the Total Environment, 677, 19, 2019.

17. FENG C., WANG M. Journey for green development transformation of China's metal industry: A spatial econometric analysis. Journal of Cleaner Production, 225, $1105,2019$.

18. FENG Y.J., ZHONG S.Y., LI Q.Y., ZHAO X.M., DONG $X$. Ecological well-being performance growth in China (1994-2014): From perspectives of industrial structure green adjustment and green total factor productivity. Journal of Cleaner Production, 236, 117556, 2019.

19. SHAO S., LUAN R.R., YANG Z.B., LI C.Y. Does directed technological change get greener: Empirical evidence from Shanghai's industrial green development transformation? Ecological Indicators, 69, 758, 2016.

20. CHUNG Y.H., FÄRE R., GROSSKOPF S. Productivity and Undesirable Outputs: A Directional Distance Function Approach. Microeconomics, 51 (3), 229, 1997.

21. FÄRE R., GROSSKOPF S., JR CAP. Environmental production functions and environmental directional distance functions. Energy, 32 (7), 1055, 2007.

22. CHEN S.Y. Energy Consumption, $\mathrm{CO}_{2}$ Emission and Sustainable Development in Chinese Industry. Economic Research Journal, 4, 41, 2009.

23. LIN B.Q., LIU H.X. Do energy and environment efficiency benefit from foreign trade? Economic Research Journal, 50 (09), 127, 2015.

24. LI J.L., XU B. Curse or blessing: how does natural resource abundance affect green economic growth in China? Economic Research Journal, 53 (09), 151, 2018.

25. WANG Y.J., YU W. Spatial Econometric Study on the Convergence of Provincial Green Total Factor Productivity in China. Nanjing Journal of Social Sciences, 11, 31, 2016.

26. JIN G., SHEN K.R., LI J. Interjurisdiction political competition and green total factor productivity in China: An inverted-U relationship. China Economic Review, https://doi.org/10.1016/j.chieco.2018.09.005, 2018.

27. NIE Y.L., WEN H.W. Green economic efficiency of Chinese city at the level of municipality or above. China Population, Resources and Environment, 25 (S1), 409, 2015.

28. LIU W., ZHAN J.Y., ZHAO F., WANG P., LI Z.H., TENG Y.M. Changing trends and influencing factors of energy productivity growth: A case study in the Pearl River Delta Metropolitan Region. Technological Forecasting \& Social Change, 137, 1, 2018.

29. FENG C., HUANG J.B., WANG M. The sustainability of China's metal industries: features, challenges and future focuses. Resources Policy, 60, 215, 2019.

30. FU J.Y., GENG Y.Y. Public participation, regulatory compliance and green development in China based on 
provincial panel data. Journal of Cleaner Production, 230, 1344, 2019.

31. YU Y.Z., YANG X.Z., ZHANG S.H. Research on the characteristics of time and space conversion of China's economy from high-speed growth to high-quality development. The Journal of Quantitative \& Technical Economics, 36 (06), 3, 2019.

32. CECCHINI L., VENANZI S., PIERRI A., CHIORRI M. Environmental efficiency analysis and estimation of $\mathrm{CO}_{2}$ abatement costs in dairy cattle farms in Umbria (Italy): A SBM-DEA model with undesirable output. Journal of Cleaner Production, 197 (1), 895, 2018.

33. CHEN C.F. China's industrial green total factor productivity and its determinants - an empirical study based on ML index and dynamic panel data model. Statistical Research, 33 (03), 53, 2016.

34. XIANG P.C., XIE Y.X., LI Z.Y. GTFP and influencing factors of construction industry from low carbon perspective. Journal of Industrial Technological Economics, 38 (08), 57, 2019.
35. WANG Y., SUN X.H., GUO X. Environmental regulation and green productivity growth: Empirical evidence on the Porter Hypothesis from OECD industrial sectors. Energy Policy, 132, 611, 2019.

36. LIN B.Q., CHEN Z. Does factor market distortion inhibit the green total factor productivity in China? Journal of Cleaner Production, 197, 25, 2018.

37. TAO J., HO C.Y., LUO S.G., SHENG Y. Agglomeration economies in creative industries. Regional Science and Urban Economics, 77, 141, 2019.

38. LIN B.Q., TAN R.P. Economic agglomeration and green economy efficiency in China. Economic Research Journal, 54 (02), 119, 2019.

39. TONE K. A slacks-based measure of efficiency in data envelopment analysis. European Journal of Operational Research, 130 (3), 498, 2011.

40. ZHANG J., WU G.Y., ZHANG J.P. The estimation of China's provincial capital stock: 1952-2000. Economic Research Journal, 10, 35, 2004. 